\title{
Preparation, Characterization and Adsorption Study of Granular Activated Carbon/Iron oxide composite for the Removal of Boron and Organics from Wastewater
}

\author{
Augustine Chioma Affam ${ }^{1 *}$, Chee Chung Wong ${ }^{1}$, Mohammed A. B. Seyam ${ }^{1}$, Chelsea Ann \\ Anak Frederick Matt ${ }^{1}$, Josephine Lantan Anak Sumbai ${ }^{1}$, and Abdullahi Mohammed \\ Evuti $^{2}$ \\ ${ }^{1}$ Civil Engineering Department, School of Engineering and Technology, University College of \\ Technology Sarawak, 96000 Sibu, Sarawak, Malaysia \\ ${ }^{2}$ Chemical Engineering Department, University of Abuja, P.M.B. 117, Abuja, Nigeria
}

\begin{abstract}
Boron and organics maybe in high concentration during production of oil and gas, fertilizers, glass, and detergents. In addition, boron added to these industrial processes may require to be removed by the wastewater treatment plant. The preparation, characterization and application of iron oxide-activated carbon composite for removal of boron and COD was studied. The one variable at a time (OVAT) method was implemented to obtain desirable operating conditions (adsorbent dosage $5 \mathrm{~g} / \mathrm{L}$, reaction time $2 \mathrm{~h}$, agitation speed $100 \mathrm{rpm}$, $\mathrm{pH} 5$ for COD removal and $\mathrm{pH} 9$ for boron removal). It was found that boron and organics present in a sample wastewater may require to be treated separately to remove the contaminants. The study achieved 97 and $70 \%$ for boron and COD removal, respectively. Adsorption as an alternative cheap source of treatment and its practicability for small communities is recommended as effective in removal of contaminants from river water.
\end{abstract}

\section{Introduction}

The presence of boron and high organic concentration in wastewater is particularly of interest because of its toxic nature and at the same time beneficial use in some other situations. Its presence in surface water occurs frequently as a consequence of the discharge of treated sewage effluents. Boron and organics are found in nature in the underground aquifers and this basically is dependent on the locality and its environmental geological features. World Health Organization (WHO) has provided a guideline for the boron concentration in drinking water to be less than $0.5 \mathrm{mg} / \mathrm{L}$. In irrigation water, boron below $1 \mathrm{mg} / \mathrm{L}$ could be beneficial and above $1 \mathrm{mg} / \mathrm{L}$ is termed toxic [1]. In terms of being beneficial, boron available as boric acid could be absorbed for development of chemical and biological structures of plants. Its deficiency may cause a reduction in its growth ability

\footnotetext{
* Corresponding author: author@ucts.edu.my or affamskii@yahoo.com
} 
and reproduction [2]. Boron can be easily leached and requires to be replaced in plant nutrition and development [3]. Organics maybe in high concentration during production of fertilizers, glass, detergents etc. In addition, boron added to these industrial processes may require to be removed by the wastewater treatment plant. Treatment of this type of industrial wastewater using various methods have been reported [4-10]. However, applying cheap and easy to handle treatment processes may still require more studies. Removal of boron and organics simultaneously may be necessary and has not been reported in literature. In this study, the focus is to examine the contaminants in a sample wastewater and to treat same for removal of boron and organics.

This study addresses two main issues. The first is to characterize the granular activated carbon/iron oxide composite and the wastewater composition, and to eventually treat the wastewater in order to remove boron and organics present in the sample using activated carbon/iron composite adsorbent through adsorption process. The application of activated carbon/iron oxide for sorption of phenol and other pollutants from water has been reported [11]. The availability of micropores and large surface area are characteristics of activated carbon. Modification of the surface usually increases the adsorption capacity and efficiency of the composite material. Iron oxide has been found to perform well when combined with activated carbon as against other oxides e.g. aluminum oxide, titanium oxide [11], and can be reused after each application, thus making it cheaper and easier to handle. This research investigated the performance of the combined activated carbon/iron oxide composite for adsorption of boron and organics contained in a sample wastewater. It is pertinent to obtain desirable operating conditions that will remove the highlighted contaminants in the selected wastewater.

\section{Materials and methods}

\subsection{Chemicals}

Iron (III) oxide was purchased from Sigma Aldrich, UK, BoroVer 3 Boron Reagent Powder Pillows and COD regent was obtained from $\mathrm{HACH}$, USA.

\subsection{Analytical Methods}

Chemical oxygen demand (COD) was determined according to the Standard Method 5220 [12]. Boron concentration was determined according to Carmine Method 8015 [12]. The pH measurements were done using a pH meter SENION MM374 Bench Top Multi Parameter Meter HACH Company, USA. Biodegradability was measured by 5-day biochemical oxygen demand $\left(\mathrm{BOD}_{5}\right)$ test according to the Standard Methods [12]. Scanning electron Microscope JSM-6010PLUS/LV, JEOL, USA was used to obtain the morphology of the composite. Brunauer-Emmett-Teller (BET) surface area apparatus (ASAP 2000, Micrometrics, USA) was used for obtaining the adsorbent morphology.

\subsection{Wastewater Composition}

The wastewater was collected from the Rajang River in Sibu downstream area. The composition of the wastewater is shown in Table 1. The wastewater sample was analysed generally following the Standard Methods for Examination of Wastewater [12]. 


\subsection{Preparation of Granular Activated Carbon/Iron Oxide Composite}

The preparation of the adsorbent was done according to the method adopted by Abussaud et al. [13] with a little modification. This is as shown in Fig. 1.

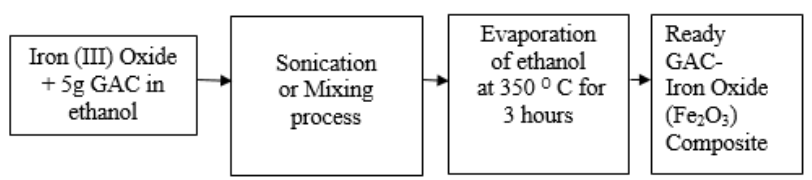

Fig. 1: Procedure for adsorbent preparation.

Table 1. Composition of Wastewater.

\begin{tabular}{|c|c|}
\hline Parameter & Concentration \\
\hline Boron & $80 \mathrm{mg} / \mathrm{L}$ \\
\hline $\mathrm{pH}$ & 7.26 \\
\hline COD & $548 \mathrm{mg} / \mathrm{L}$ \\
\hline BOD & $9.6 \mathrm{mg} / \mathrm{L}$ \\
\hline UV $_{254}$ & $0.653 \mathrm{~cm}^{-1}$ \\
\hline Turbidity & $92 \mathrm{FAU} / \mathrm{NTU}$ \\
\hline EC & $14.68 \mu \mathrm{s} / \mathrm{cm}$ \\
\hline TDS & $9.84 \mathrm{mg} / \mathrm{L}$ \\
\hline Colour & $98 \mathrm{pt}-\mathrm{co}$ \\
\hline TSS $(\mathrm{mg} / \mathrm{l})$ & 2030 \\
\hline
\end{tabular}

\subsection{Experimental procedure}

The wastewater collected from Rajang River was sent to the Environmental Laboratory of University College of Technology Sarawak and stored at $4^{\circ} \mathrm{C}$ until needed. Where sample $\mathrm{pH}$ required adjustment, 2 to 3 drops of $1 \mathrm{M} \mathrm{H}_{2} \mathrm{SO}_{4}$ or $\mathrm{NaOH}$ was used. Adsorbent concentration, time, speed of agitation, $\mathrm{pH}$ were varied while the wastewater concentration remained same. A $250 \mathrm{ml}$ Erlenmeyer flask containing $100 \mathrm{ml}$ of the wastewater was placed on a desk orbital shaker allowing varying time intervals before removal. This was according to the one variable at a time (OVAT) design of experiment. Samples were centrifuged at $5000 \mathrm{rpm}$ using a bench centrifuge for thorough separation of supernatants for analysis. Results were obtained in duplicate analysis for consistency.

\section{Results and discussions}

\subsection{Effect of pH}

Understanding the effect of $\mathrm{pH}$ is a very vital component in wastewater treatment in order to determine the existing charges on the surfaces of adsorbents [14]. Fig. 2 shows COD removal efficiency at various $\mathrm{pH}$ values from 2 to 9 . Other operating conditions of the system was $100 \mathrm{rpm}, 30$ to $120 \mathrm{~min}$ and $5 \mathrm{~g} / \mathrm{L}$ adsorbent dosage. It was observed that the removal efficiency was strongly dependent on the $\mathrm{pH}$ of the solution. Based on the obtained result, $\mathrm{pH} 5$ has the highest removal of $54 \%$ for COD. At $\mathrm{pH}$, up to $97 \%$ of boron was removed as shown in Fig. 3. It was reported that the removal of boron when optimised occurs around $\mathrm{pH} 9-9.5$ [15]. High boron removal of more than $70 \%$ was achieved above pH 11 [16]. 


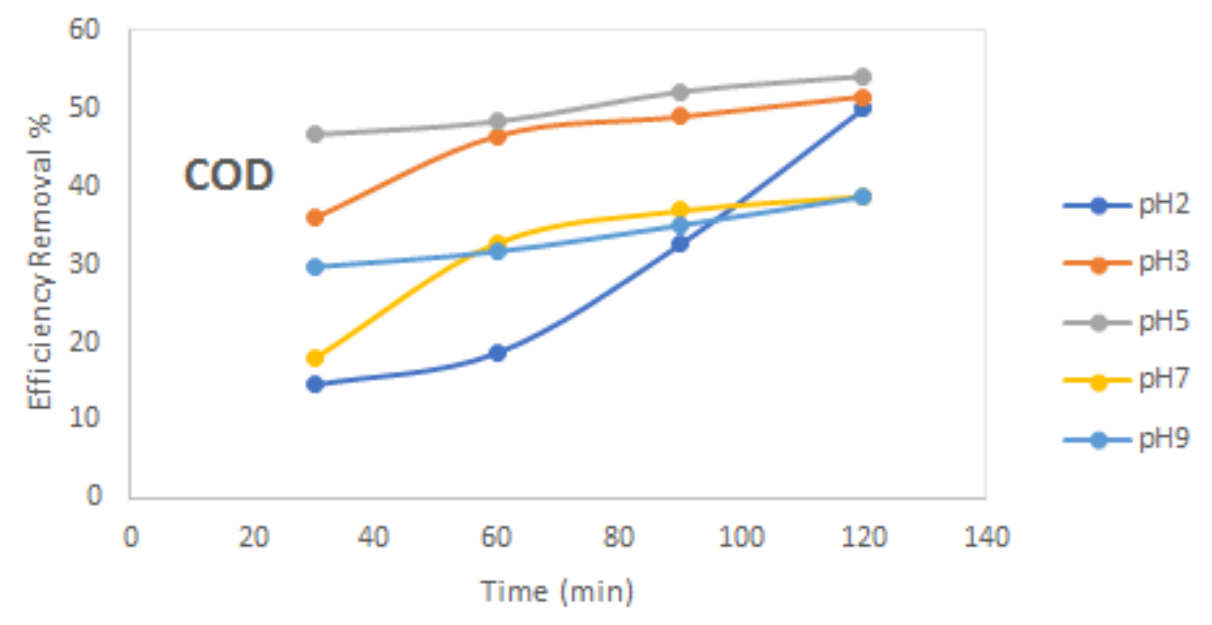

Fig. 2. COD removal efficiency from $\mathrm{pH} 2$ to 9.

\subsection{Effect of Agitation Speed}

Optimum speed of agitation is essentially needed to maximize the interactions between wastewater sample and adsorption sites of adsorbents in a solution. In this study, the effect of agitation speed (100 to $300 \mathrm{rpm}$ ) on adsorption of the contaminants was investigated. The percentage removal of COD and boron under selected operating conditions (30 to 120 min and $5 \mathrm{~g} / \mathrm{L}$ adsorbent dosage) are shown in Fig. 4 and 5. It was found that COD and Boron removal efficiencies increased with an increase from 100 to $300 \mathrm{rpm}$. This increase can be explained by the fact that for a relatively increase in speed, the system is completely mixed with probably more energy used. With further increase in agitation speed rate from 100 to $300 \mathrm{rpm}$, the effect on the adsorption became comparatively negligible; since the system was well mixed under a comparatively high shaking rate [17]. As a consequence, a shaking rate of $100 \mathrm{rpm}$ was selected as desirable for subsequent studies because it was obvious that there was no significant increase or effect on the process. A research reported that, higher mass transfer rate and removal efficiency were obtained when the solution was agitated at higher mechanical speed [18]. 


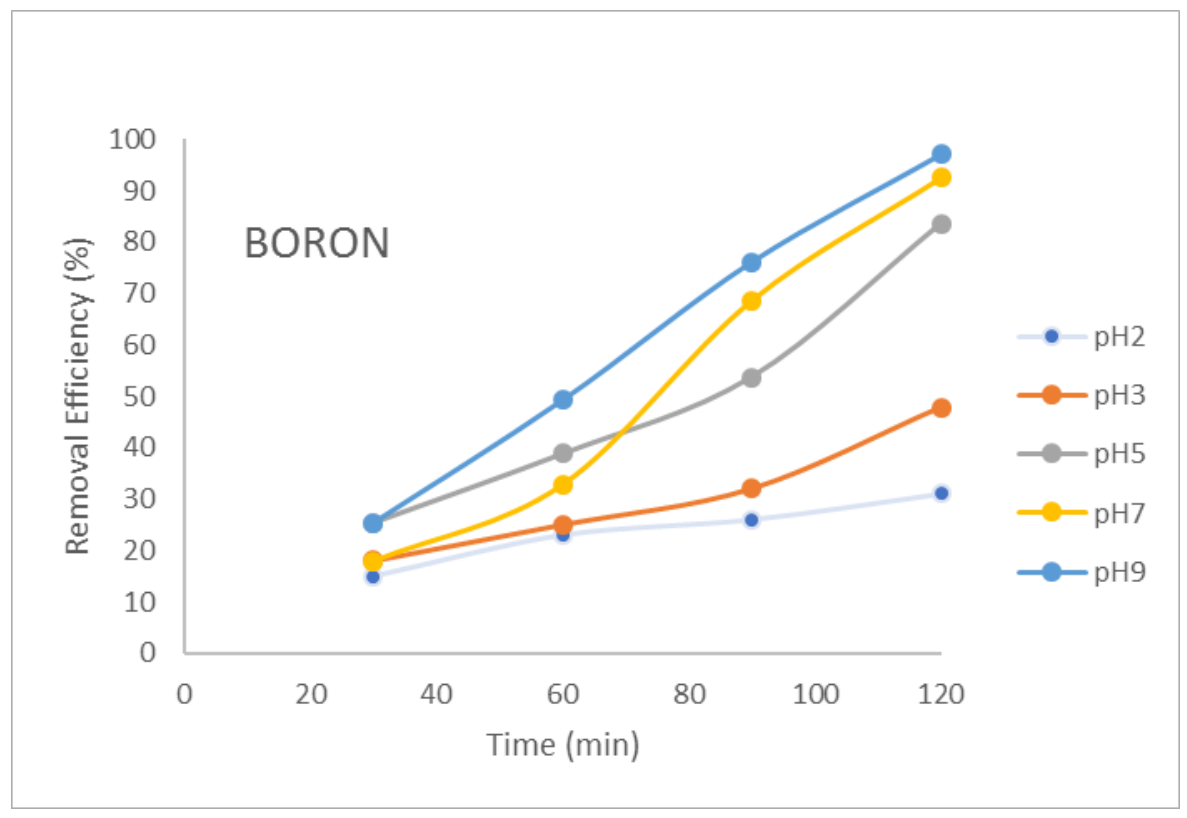

Fig. 3. Boron removal efficiency from $\mathrm{pH} 2$ to 9.

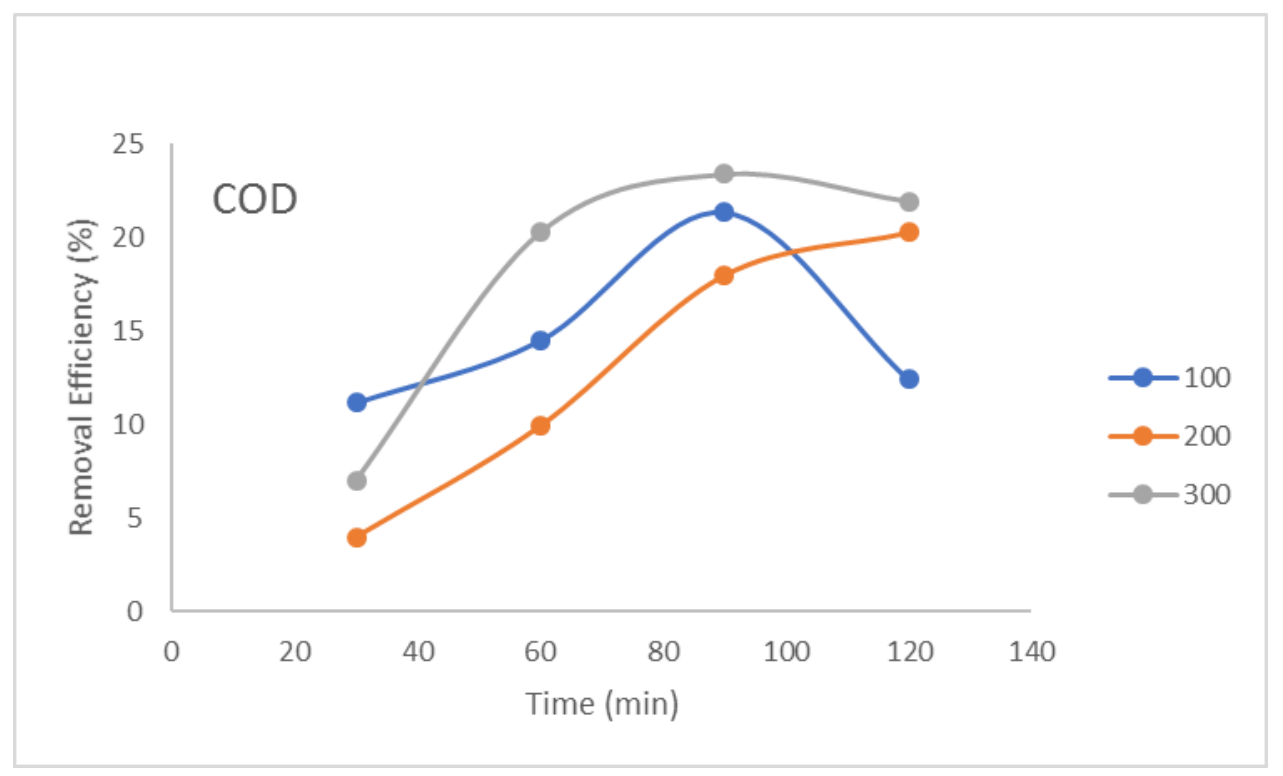

Fig. 4. COD removal efficiency from 100 to 300 rotor speed per minute. 


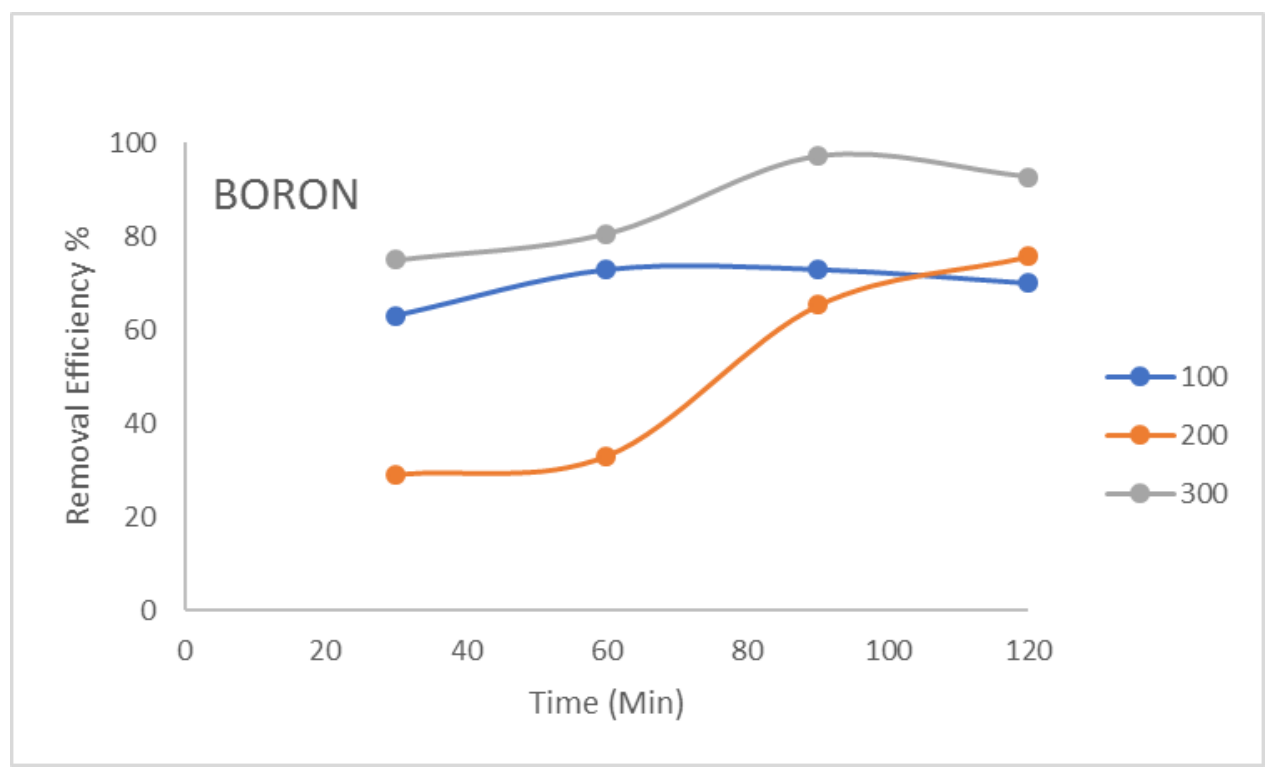

Fig. 5. Boron removal efficiency from 100 to 300 rotor speed per minute.

\subsection{Effect of Contact Time}

The COD and boron removal were studied at different contact time duration. Fig. 6 shows the effect of time on the removal of organics and boron at different time intervals from 1 to $4 \mathrm{~h}$. Other operating conditions of the system were $100 \mathrm{rpm}, 1$ to $4 \mathrm{~h}$ and $5 \mathrm{~g} / \mathrm{L}$ adsorbent dosage. The removal efficiency increased from 1 until 2 $\mathrm{h}$ for COD and boron, thereafter a drop in performance was observed from the 3 until $4 \mathrm{~h}$. This suggests that the adsorbent can easily and rapidly adsorb contaminants due to high specific surface area at the initial phase and gradually become fully saturated when it reaches the equilibrium phase in a known time interval. From the results obtained from the experiment, contact time of $2 \mathrm{~h}$ removed COD and boron of 70 and $97 \%$, respectively (Fig. 6).

\subsection{Isotherm Model}

In order to analyse the removal of the pollutants in terms of COD and boron, isotherm studies were conducted. Langmuir and Freundlich isotherms represents the equilibrium distribution of metal ions between the solid and liquid phases, de fining the correlation with the amount of adsorption and liquid phase concentration. The Langmuir isotherm is based on the assumption that the adsorption will take place only at specific localized sites on the surface and the saturation coverage corresponds to complete occupancy of these sites, and each site can accommodate only one molecule and the surface is energetically homogeneous [19]. The adsorption isotherm for heterogeneous surface is most times described by the Freundlich adsorption isotherm, whose main assumption is that the metal ions can be applied for multilayer sorption [20]. To determine which model describes the removal of pollutants, the data from this experiment was fitted to the models separately. 
The Langmuir isotherm can expressed in the equation 1.

$$
C_{e} / q_{e}=1 / b q_{\max }+C_{e} / q_{\max }
$$

Where the qmax $(\mathrm{mg} / \mathrm{g})$ is the maximum adsorption capacity, the $b$ is the Langmuir constant $(\mathrm{L} / \mathrm{mg})$. The $\mathrm{q}_{\max }$ and $b$ are obtained from the linear regression plot of $\mathrm{C}_{\mathrm{e}} / q_{\mathrm{e}}$ Versus $\mathrm{C}_{\mathrm{e}}$.

The Fruendlich is expressed by the equation 2.

$$
\ln q_{e}=\ln \quad K_{F}+1 / n \ln \quad C_{e}
$$

where $K_{F}$ and $\mathrm{n}$ are constants from Fruendlich equation. $K_{F}$ represents the capacity of the adsorbent for the adsorbate, and $1 / \mathrm{n}$ is the reciprocal of reaction order. A linear regression plot of $\ln q_{\mathrm{e}}$ versus $\ln C_{e}$ gives the $K_{F}$ and $\mathrm{n}$ values required [20].

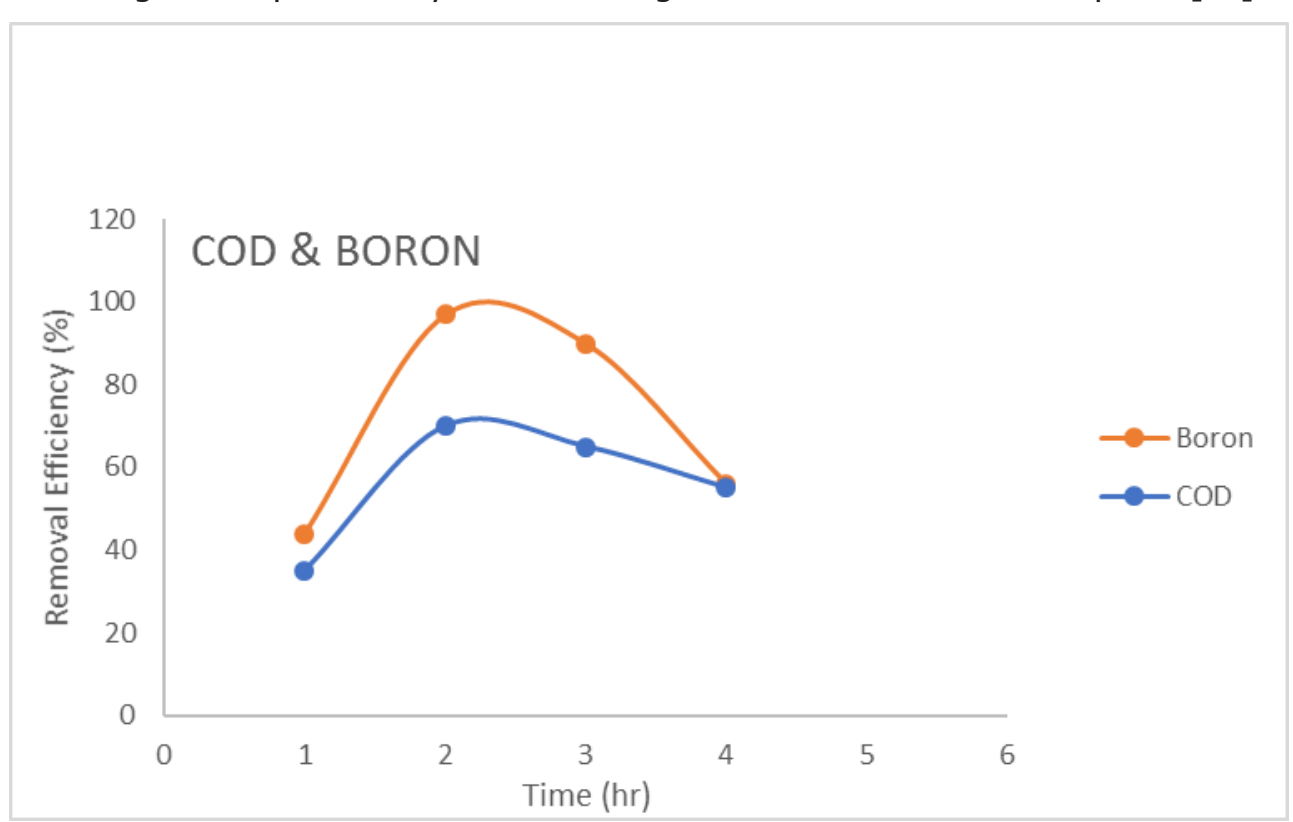

Fig. 6. COD and Boron removal efficiency at 1 to $4 \mathrm{~h}$ contact time.

In this study, the obtained isotherm model results show that both Langmuir and $\left(R^{2}=0.9997\right)$ and Fruendlich $\left(R^{2}=0.9997\right)$ for COD removal and Langmuir $\left(R^{2}=0.8451\right)$ and Fruendlich $\left(R^{2}=0.9049\right)$ for boron removal. It was observed that in both cases the data fits well for the adsorption of COD and boron onto the GAC/iron oxide, respectively. Thus, it shows that the adsorption process was occurring on both homogeneous and heterogeneous surfaces of the adsorbent composite. Masindi and Gitari [21] reported similar findings in their work.

\subsection{Scanning Electron Microscope}

The analysis by scanning electron microscope (SEM) of the adsorbent demonstrates that the mechanism of non-diffusive sorption is involved since the iron oxide was adsorbed on 
the porous matrix of the activated carbon. The SEM obtained the morphology of the adsorbent before and after preparation as seen in Fig. 7 and 8 for commercial GAC and GAC/iron oxide, respectively. The figures show that the activated carbon had an irregular and porous surface indicating relatively high surface areas.

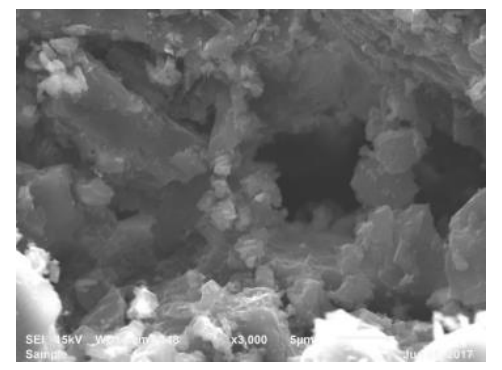

Fig. 7. GAC.

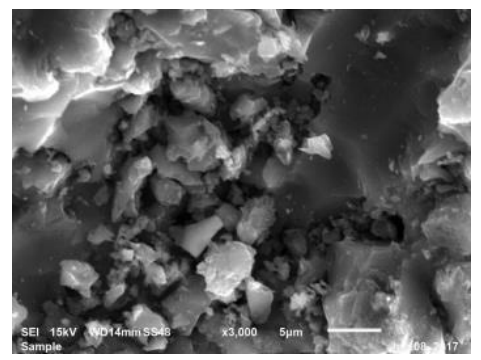

Fig. 8. GAC/Iron oxide.

\subsection{Brunauer-Emmett-Teller (BET) Characteristics}

The BET analysis gives the GAC/iron oxide composite surface area, which is the sum of micropore area and external surface area. The large pore diameter of composite could permit the pollutants (organics and boron) to diffuse into the mesoporous material pore channels. Thus, pollutants can be adsorbed onto the inner and outer structures of the adsorbent composite. Initial BET surface area for the GAC was $995.56 \mathrm{~m}^{2} / \mathrm{g}$ whereas the GAC/iron oxide was $1474.36 \mathrm{~m}^{2} / \mathrm{g}$. The increase in the surface area with the modification using iron oxide was very obvious. In order to improve the adsorbent particle size, it was initially further reduced using a blender when it was supplied. An increase in surface area will correspondingly increase the adsorption capacity of an adsorbent.

\section{Conclusions}

The study was able to investigate the possibility of simultaneous removal of boron and organics from a sample wastewater collected from a primary source of raw water namely the Rajang river. Under the desirable operating condition obtained, it was found the maximum COD removal efficiency was $70 \%$ at $\mathrm{pH} 5$ and $97 \%$ for boron removal at $\mathrm{pH} 9$. This implies that both pollutants may require to be treated separately to remove them efficiently. In addition, when $\mathrm{pH}$ is in the acidic region it will be more favourable for the removal of COD compared to removing boron. However, the study shows that granular activated carbon/iron oxide composite can be used for removal of low concentration of boron and organics that maybe in wastewater.

The authors are grateful to the management of University College of Technology Sarawak (UCTS) for providing the internal grant No. UCTS/RESEARCH/1/2016/10> (01) to support this work and also for the provision of facilities to conduct this research.

\section{References}

1. R.O. Nable, G.S. Banuelos, J.G. Paull, Plant and Soil 193, 181 (1997)

2. A.E. Yilmaz, R. Boncukcuoglu, M.M. Kocakerim, Desalination 230, 288 (2008)

3. M. Tarig, C.J.B. Mott, Asian J. Plant Sci. 5, 963 (2006) 
4. K.L. Benko, J.E. Drewes, Environ. Eng. Sci. 25, 239 (2008)

5. D.L. Shaffer, L.H. Arias Chavez, M. Ben-Sasson, S. Romero-Vargas Castrillón, N.Y. Yip, M. Elimelech, Environ. Sci. Technol. 47, 9569 (2013)

6. F.R. Ahmadun, A. Pendashteh, L.C. Abdullah, D.R.A. Biak, S.S. Madaeni, Z.Z. Abidin, J. Hazard. Mater. 170, 530 (2009)

7. J.Q. Jiang, Y. Xu, K. Quill, J. Simon, K. Shettle, Environ. Chem. 3, 350 (2006)

8. G. Sayiner, F. Kandemirli, A. Dimoglo, Desalination 230, 205 (2008)

9. M.H. Isa, E.H. Ezechi, Z. Ahmed, S.F. Magram, S.R.M. Kutty, Wat. Res. 51, 113 (2013)

10. N. Esmaeilirad, K. Carlson, P.O. Ozbek, J. Hazard. Mater. 283, 721 (2015)

11. B. Abussaud, H. A. Asmaly, Ihsanullah, T. A. Saleh, V. K. Gupta, T. laoui, M. A. Atieh. J. Mol. Liq. 213, 351 (2016)

12. APHA, AWWA, WPCF, Washington, DC, USA (2005)

13. H.A. Asmaly, Ihsanullah, B. Abussaud, T.A. Saleh, T. Laoui, V.K. Gupta, M.A. Atieh, Desalin. Water Treat. 57 (2015)

14. M. Ahmaruzzaman, V. K. Gupta, Ind. Eng. Chem. Res. 50, 13589 (2011)

15. A. E. Yilmaz, R. Boncukcuoğlu, M. M. Kocakerm, E. Kocadağistan, Desalination, 230, 288 (2008)

16. L. A. Richards, M. Vuachère, A. I. Schäfer, Desalination, 261, 331 (2010)

17. M. V. Karkare, Z. V. P. Murthy, J. Ind. Eng. Chem.18, 1301 (2012)

18. M. Shams, M. H. Dehghani, R. Nabizadeh, A. Mesdaghinia, M. Alimohammadi, A. A. Najafpoor, J. Mol. Liq. 224,151 (2016)

19. R. Sime, The Langmuir Adsorption Isotherm, 7 (2000)

20. A. Dada, A. Olalekan, A. Olatunya, O. Dada, IOSR J. Appl. Chem. 3, 38 (2012)

21. V. Masindi, M. W. Gitari, 2017. Removal of boron from aqueous system using magnesite. J. Wat. Reuse Desalin. 7, 205 (2017) 